\title{
Third-generation oxygen amperometric biosensor based on Trametes hirsuta laccase covalently bound to graphite electrode
}

\author{
${ }^{a}$ Cristina Gutierrez-Sanchez, ${ }^{b}$ Sergey Shleev, ${ }^{a}$ Antonio L. De Lacey, ${ }^{a}$ Marcos Pita* \\ a Instituto de Catalisis y Petroleoquimica, CSIC, C/Marie Curie 2, L10, 28049 Madrid, Spain
}

b Department of Biomedical Sciences, Faculty of Health and Society, Malmö University, 20560 Malmö, Sweden

Received 24 February 2014; Revised 8 April 2014; Accepted 9 April 2014

\begin{abstract}
The response of low-density graphite electrodes hosting Trametes hirsuta laccase in a direct electron transfer regime is presented for real-time analysis of $\mathrm{O}_{2}$ concentrations. The use of contrasting immobilisation methods developed for biocathodes affords good reproducibility and reliability of the amperometric biosensor, which shows a limit of detection below $1 \mu \mathrm{M}$ and a sensitivity slightly higher than $60 \mathrm{nA} \mathrm{cm}^{-2} \mathrm{M}^{-1}$.

(c) 2014 Institute of Chemistry, Slovak Academy of Sciences
\end{abstract}

Keywords: oxygen biosensor, direct electron transfer, laccase, bioelectrocatalysis

Biocatalysts are biological molecules, mostly enzymes, capable of catalysing a chemical reaction. When enzymes capable of catalysing redox reactions are coupled to an electrode, a bioelectrode is generated. Bioelectrodes typically find applications in in vivo biosensing or powering implantable devices with biofuel cells, providing electrical energy by consuming biochemicals of natural origin (Katz \& Willner, 2003; Davis \& Higson, 2007; Shukla et al., 2004). The properties of biological macromolecules render them suitable as recognition units as well as signal emitters, hence fulfilling the needs for sensors development. Due to these properties, bioelectrochemical sensors are very attractive devices, which may take the place of conventional amperometric sensors, which are more prone to false positive signals or poisoning. Amperometric biosensors comprise a redox entity, generally an enzyme, and an electroactive surface capable of quantifying the redox activity of the biocatalyst (Bardeletti et al., 1991). In addition, the electrochemical biosensors can also include other elements, such as mediators to facilitate the electron transfer or stabilisers to prolong the average lifetime of the biosensors.

There has been growing interest in sensing molecular oxygen $\left(\mathrm{O}_{2}\right)$ in living systems and organisms.
Within this context, the use of redox enzymes capable of reducing $\mathrm{O}_{2}$ directly to $\mathrm{H}_{2} \mathrm{O}$ affords a great advantage against most oxidases, which produce hydrogen peroxide and may thus harm a living system. Multi-copper oxidases (MCOs) are enzymes capable of achieving such a process (Solomon et al., 1996); they are suitable for immobilisation on different types of electrodes and for establishing direct electron transfer reactions (Shleev et al., 2004). Accordingly, MCOs are good candidates for use as biosensing systems in implantable devices designed for real-time $\mathrm{O}_{2}$ monitoring. In the present work, an electrochemical $\mathrm{O}_{2}$ biosensor designed to work in acidic biofluids, using Trametes hirsuta laccase (ThLc) immobilised covalently on a low-density graphite (LDG) electrode by use of a two-step immobilisation strategy is detailed (Vaz-Dominguez et al., 2008; Gutierrez-Sanchez et al., 2012). LDG is a suitable support for ThLc immobilisation due to its high porosity and ready functionalisation, especially since its surface similarity with polyphenols enhances the orientation process with the $\mathrm{T} 1$ site facing the electrode. The immobilisation strategy comprises: $(i)$ modification of the LDG surface with the 4-aminoaryl functional groups, (ii) initial oxidisation of the ThLc sugar residues to multi-aldehyde

*Corresponding author, e-mail: marcospita@icp.csic.es 
derivatives by incubation of the enzyme in the presence of $\mathrm{NaIO}_{4}$, (iii) formation of imino bonds between the terminal amino groups existing on the electrode surface and the aldehyde groups on the enzyme surface, favouring adequate orientation of the enzyme for direct electron transfer, and $(i v)$ formation of an amide bond between some carboxylic residues on the enzyme backbone and the amino groups on the electrode by EDC-catalysed reaction.

ThLc from the basidiomycete T. hirsuta, strain T. hirsuta 56, was kindly provided by the Laboratory of Chemical Enzymology, A. N. Bach Institute of Biochemistry, Moscow, Russia. The enzyme was purified and characterised following the procedure previously reported (Shleev et al., 2004). The immobilisation strategy commenced by functionalisation of the 3-mm diameter LDG rods that served as electrodes (Sigma-Aldrich). The LDG electrodes were polished with emery paper and cleaned by sonication in a mixture of EtOH/MilliQ water $\left(\varphi_{\mathrm{r}}=1: 2\right)(18.2 \mathrm{M} \Omega \mathrm{cm})$. Next, the LDG electrodes were modified as previously detailed (Vaz-Dominguez et al., 2008). 4-Nitrobenzene diazonium salt $(2.5 \mathrm{mg}$ ) (Sigma-Aldrich) was dissolved in $0.1 \mathrm{M} \mathrm{Bu}_{4} \mathrm{NBF}_{4}(5 \mathrm{~mL})$ (Sigma-Aldrich) prepared in anhydrous $\mathrm{CH}_{3} \mathrm{CN}$ (Panreac). The pretreated electrode was immersed in $3 \mathrm{~mL}$ of the above solution and the potential was cycled twice between $+0.75 \mathrm{~V}$ and $-0.05 \mathrm{~V}$ (vs $\mathrm{Ag}|\mathrm{AgCl}| 3 \mathrm{M} \mathrm{KCl}$ ) at $200 \mathrm{mV} \mathrm{s}^{-1}$. The electrode was then transferred into a EtOH $/ \mathrm{H}_{2} \mathrm{O}\left(\varphi_{\mathrm{r}}=1: 9\right)$ solution containing $0.1 \mathrm{M} \mathrm{KCl}$ (Panreac), previously deoxygenated, and subjected to two cyclic voltammograms between $0 \mathrm{~V}$ and $-1.4 \mathrm{~V}$ (vs $\mathrm{Ag}|\mathrm{AgCl}| 3 \mathrm{M} \mathrm{KCl}$ ) at $100 \mathrm{mV} \mathrm{s}^{-1}$ for reduction of the nitro groups of the attached phenyl rings.

In parallel, ThLc was modified as follows: the hydroxyl groups of the sugar residues in the glycosylation shell of the enzyme were oxidised to aldehyde groups by adding $50 \mu \mathrm{L}$ of $47 \mathrm{mM} \mathrm{NaIO}_{4}$ (SigmaAldrich) to $22 \mu \mathrm{L}$ of $7.5 \mathrm{mg} \mathrm{mL} \mathrm{mL}^{-1}$ ThLc solution. After $30 \mathrm{~min}, 200 \mu \mathrm{L}$ of $100 \mathrm{mM}$ phosphate buffer (pH 7.0) (Panreac) was added and the aminophenylmodified electrode was immersed in the solution for $90 \mathrm{~min}$, permitting formation of imino bonds between the amino groups at the electrode surface and the aldehyde groups of the enzyme. The electrode was covered with an eppendorf tube in order to avoid rapid evaporation of the drop. Then, amide-coupling was activated by depositing on the electrode a $4.5 \mu \mathrm{L}$ drop of a $20 \mathrm{mM} N$-hydroxysuccinimide (NHS, Fluka) solution (in $10 \mathrm{mM}$ phosphate buffer, $\mathrm{pH} \mathrm{6.0)}$ and, immediately afterwards, a $5.5 \mu \mathrm{L}$ drop of a $40 \mathrm{mM} \mathrm{1-}$ (3-dimethylaminopropyl)-3-ethylcarbodiimide (EDC, Sigma-Aldrich) solution in $10 \mathrm{mM}$ of $2-(N$-morpholino $)$ ethanesulphonic acid (MES, Sigma-Aldrich) buffer ( $\mathrm{pH} 6.0)$.

The LDG electrodes modified in this way have exhibited ability to function as biofuel cell cathodes in high area electrodes (Gutierrez-Sanchez et al., 2012);

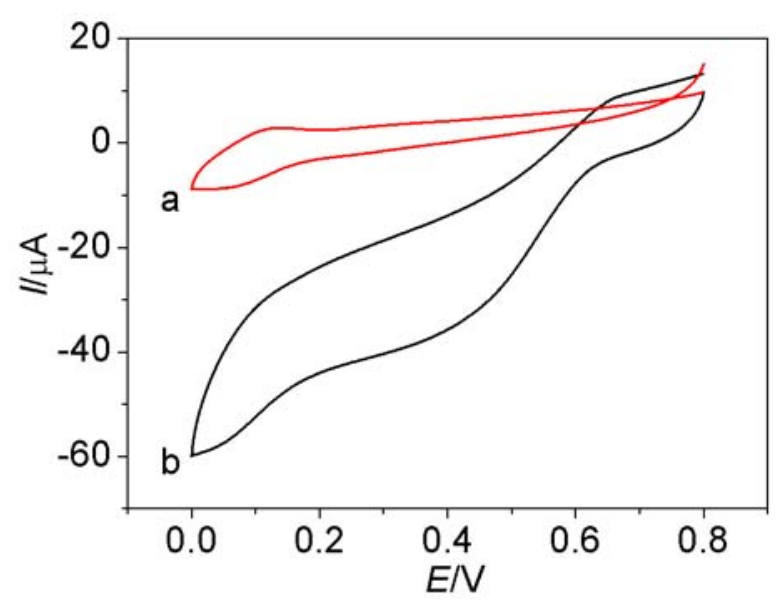

Fig. 1. CVs for $\mathrm{O}_{2}$ reduction recorded using $\mathrm{NH}_{2} / \mathrm{LDG}$ electrode (curve a) and ThLc electrode (curve b).

however, they can also serve to directly monitor the concentration of $\mathrm{O}_{2}$ dissolved in an acidic solution. This specific immobilisation procedure, designed to avoid halides inhibition, was arranged on LDG electrodes (Vaz-Dominguez et al., 2008), resulting in a chronoamperometric sensor that can provide real time $\left[\mathrm{O}_{2}\right]$ values.

The electrochemical measurements were performed in a three-electrode thermostatic electrochemical cell set at $27^{\circ} \mathrm{C}$. The electrochemical set was placed inside an anaerobic chamber affording an oxygen concentration lower than $0.1 \mathrm{mg} \mathrm{\textrm {L } ^ { - 1 }}$. The electrochemical cell was filled with $20 \mathrm{~mL}$ of an electrolyte solution at $\mathrm{pH} 4.2$ containing $50 \mathrm{mM}$ sodium acetate and $100 \mathrm{mM} \mathrm{NaClO}$ and saturated with $\mathrm{N}_{2}$. The counter electrode was a platinum wire, and the reference electrode was $\mathrm{Ag}|\mathrm{AgCl}| 3 \mathrm{M} \mathrm{KCl}$ from Bioanalytical Systems. The working electrodes used were the modified LDG electrodes as described previously. The measurements were performed with an Autolab PGSTAT12 potentiostat, using GPES 4.9 software.

The electrodes modified with ThLc were first tested by running a cyclic voltammetry (CV) (Fig. 1). Cyclic voltammograms of the modified electrodes for $\mathrm{O}_{2}$ reduction were recorded in the range of $0.8-0 \mathrm{~V}$ vs $\mathrm{Ag} / \mathrm{AgCl}$ at a $10 \mathrm{mV} \mathrm{s}^{-1}$ scan-rate in $100 \mathrm{mM}$ acetate buffer ( $\mathrm{pH} 4.2$ ) containing $100 \mathrm{mM} \mathrm{NaClO}_{4}$ enriched in $\mathrm{O}_{2}$ by passing the gas through for $10 \mathrm{~min}$ prior to the measurement. The modified electrode shows the typical cathodic response for a LDG/ThLc electrode starting at $0.6 \mathrm{mV}$ vs $\mathrm{Ag} / \mathrm{AgCl}$ (Vaz-Dominguez et al., 2008; Gutierrez-Sanchez et al., 2012), whereas a LDG electrode modified only with the aminoaryl layer $\left(\mathrm{NH}_{2} / \mathrm{LDG}\right)$ exhibits no $\mathrm{O}_{2}$ reduction ability.

Chronoamperometric measurements were performed under a bias potential of $0.2 \mathrm{~V}$ vs $\mathrm{Ag} / \mathrm{AgCl}$ and $800 \mathrm{~min}^{-1}$ rotation of the working electrode. The signal was allowed to reach a plateau, then the biosensor was calibrated by the addition of different aliquots 
(A)

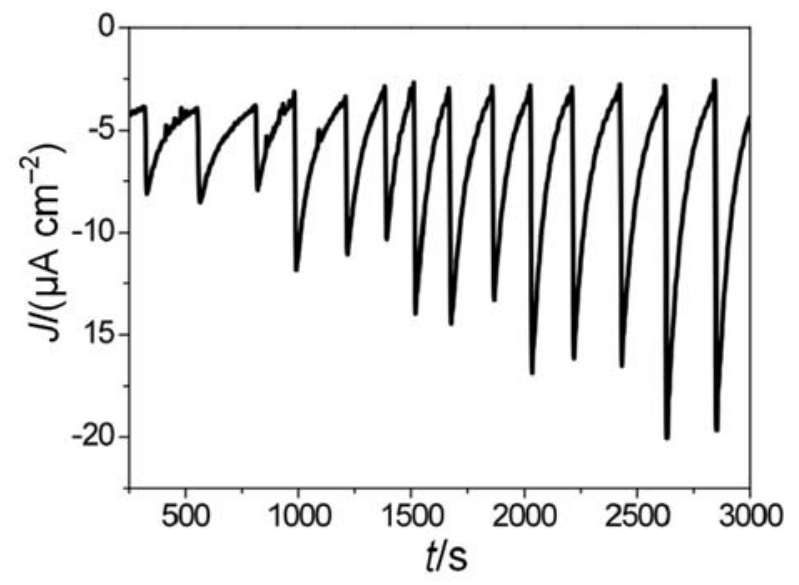

(B)

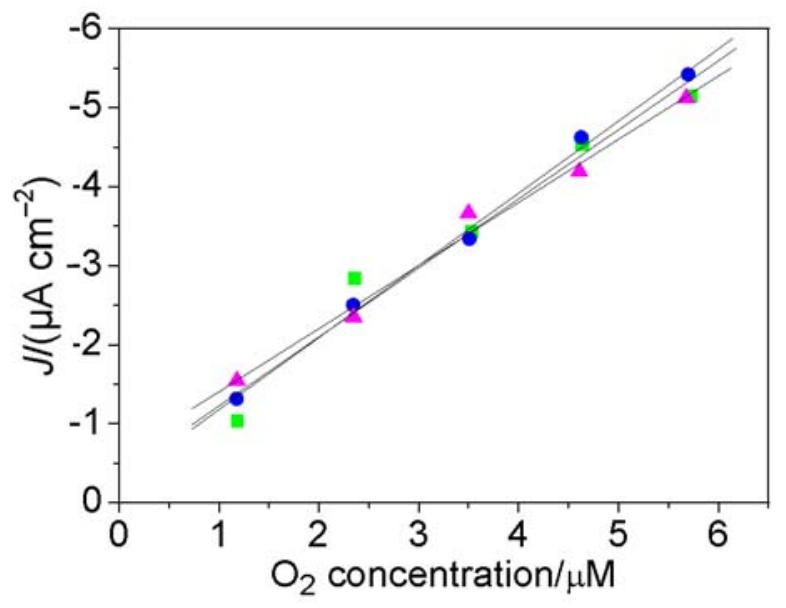

Fig. 2. (A) Typical chronoamperometric response measured on ThLc/LDG electrode using bias potential of $0.2 \mathrm{~V}$ vs $\mathrm{Ag} / \mathrm{AgCl}$ with rotation speed of $800 \mathrm{~min}^{-1}$ at $27^{\circ} \mathrm{C}$. Electrolyte: $50 \mathrm{mM}$ sodium acetate ( $\mathrm{pH} 4.2)$ containing $100 \mathrm{mM} \mathrm{NaClO}_{4}, \mathrm{~N}_{2}$-saturated anaerobic chamber; $\mathrm{O}_{2}$-saturated buffer aliquots were added in triplicate ranging from $5 \mu \mathrm{L}$ to $100 \mu \mathrm{L}$. (B) Linear regression of $\mathrm{O}_{2}$ concentration in triplicate.

of the same buffer used as electrolyte but saturated with $\mathrm{O}_{2}$. The signal for each aliquot was measured three times. The values for each addition were those recorded $3 \mathrm{~s}$ after the aliquot addition and with the initial current value measured during the chronoamperometry subtracted.

The modified electrodes were first tested in the electrochemical cell saturated with $\mathrm{N}_{2}$ and inside the anaerobic chamber. The initial value after stabilisation was considered to be the background value. Different volumes of the same buffer saturated with $\mathrm{O}_{2}$ were injected, each three times, ranging from $1 \mu \mathrm{L}$ to $100 \mu \mathrm{L}$ (Fig. 2A). A rapid response proportional to the
(A)

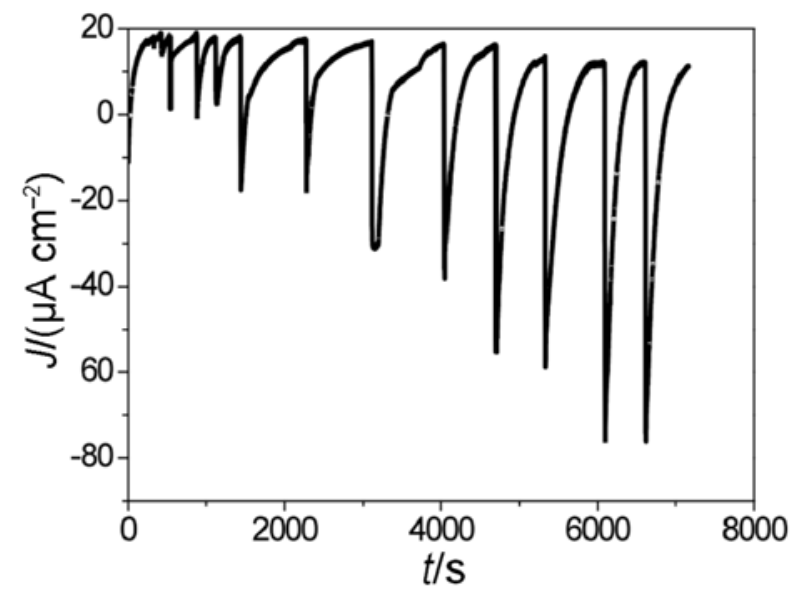

(B)

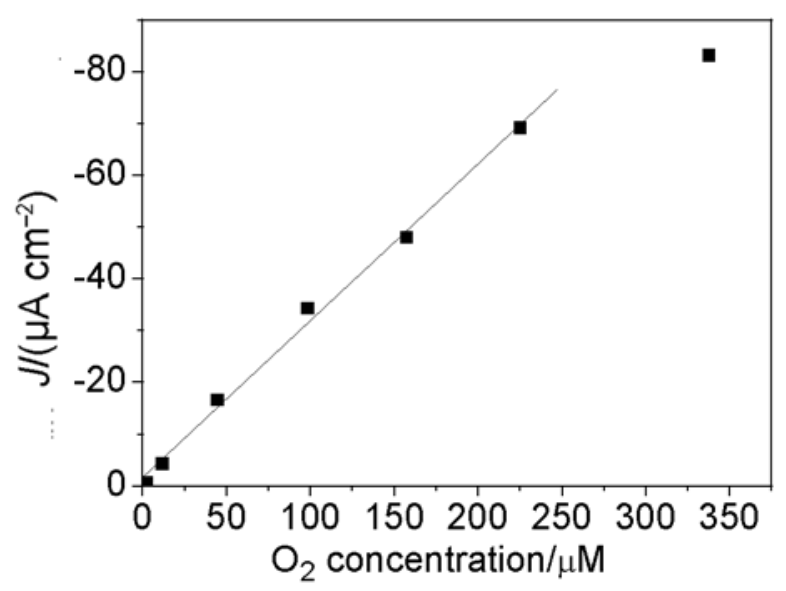

Fig. 3. (A) Typical chronoamperometric response measured on ThLc/LDG electrode using bias potential of $0.2 \mathrm{~V}$ vs $\mathrm{Ag} / \mathrm{AgCl}$ under rotation speed of $800 \mathrm{~min}^{-1}$ at $27^{\circ} \mathrm{C}$. Electrolyte: $50 \mathrm{mM}$ sodium acetate ( $\mathrm{pH} 4.2)$ containing $100 \mathrm{mM} \mathrm{NaClO}_{4}, \mathrm{~N}_{2}$-saturated anaerobic chamber; $\mathrm{O}_{2}$-saturated buffer aliquots were added in triplicate ranging from $10 \mu \mathrm{L}$ to $3000 \mu \mathrm{L}$. (B) Linear interval extracted from plot $\mathrm{A}$.

amount of the $\mathrm{O}_{2}$-saturated buffer added to the electrochemical cell was observed. The response afforded by three different electrodes to the chronoamperometric calibration showed a high degree of coherence, as can be seen in Fig. 2B.

The dependence of the current intensity upon changing $\left[\mathrm{O}_{2}\right]$ was determined by subtracting the background value from the peak values obtained $3 \mathrm{~s}$ after each injection during the chronoamperometry, thus minimising measurement error. The limit of detection measured for this $\mathrm{O}_{2}$ biosensor was $(0.7 \pm 0.2) \mu \mathrm{M}$ and the sensitivity was $(6.4 \pm 0.4) \times 10^{-8} \mathrm{~A} \mathrm{~cm}^{-2} \mathrm{M}^{-1}$. The linear range of the biosensor was also determined. 
Aliquots of $\mathrm{O}_{2}$-saturated buffer ranging from $10 \mu \mathrm{L}$ to $3000 \mu \mathrm{L}$ were added to the solution (Fig. 3A). As a result, the bioelectrode gave a linear response up to $220 \mu \mathrm{M}$ of $\mathrm{O}_{2}$ (Fig. 3B), which corresponds to the natural concentration of an aqueous solution in equilibrium with air. The operational stability of the LDGlaccase-modified electrode following the present procedure was investigated previously (Gutierrez-Sanchez et al., 2012).

The performance of the laccase biosensor presented improvements over other biosensors such as that developed for Rhus vernificera laccase under a mediated electron transfer regime ( $\mathrm{Wu}$ et al., 2010), in which a limit of detection of $(10 \pm 2) \mu \mathrm{M}$ and a sensitivity equal to $9 \times 10^{-8} \mathrm{~A} \mathrm{~cm}^{-2} \mathrm{M}^{-1}$ was achieved, or another developed for a different multi-copper oxidase bilirubin oxidase (Pita et al., 2013), in which a limit of detection of $(6 \pm 1) \mu \mathrm{M}$ and a sensitivity of $(4.5 \pm 0.1) \times 10^{-8} \mathrm{~A} \mathrm{~cm}^{-2} \mathrm{M}^{-1}$ was achieved. This improvement may be attributed to the rotating measures, which minimise the diffusion effects of mass transfer to the electrode surface. The biosensor presented here may compete in performance with commercial Clark-type microelectrode $\mathrm{O}_{2}$ amperometric as well as optical sensors, although time stability has yet to be improved.

The present work shows that ThLc is not only suitable as a biocatalyst for biocathodes of biofuel cells but can also function as an $\mathrm{O}_{2}$ biosensor. ThLc has exhibited excellent biosensor properties, mainly against polyphenols (Gupta et al., 2003), but has hardly been used as an $\mathrm{O}_{2}$ biosensor (Gupta et al., 2004). The immobilisation strategy here presented affords a reliable $\mathrm{O}_{2}$ biosensor that can be applied to acidic biofluids or other acidic solutions. Future studies will pursue the development of biosensors based on laboratorydeveloped mutant laccases (Mate et al., 2013) which are active at neutral $\mathrm{pH}$ values.

Acknowledgements. This work was funded by the FPY project FP7-PEOPLE-2013-ITN-607793, MINECO-CTQ201232448. M.P. wishes to acknowledge assistance received from the 2009 Ramon y Cajal programme from the Spanish MINECO.

\section{References}

Bardeletti, G., Séchaud, F., \& Coulet, P. R. (1991). Amperometric enzyme electrodes for substrate and enzyme activity determinations. In L. J. Blum, \& P. R. Coulet (Eds.), Biosensor principles and applications (Chapter 2, pp. 7-47). New York, NY, USA: Marcel Dekker.
Davis, F., \& Higson, S. P. J. (2007). Biofuel cells-Recent advances and applications. Biosensors and Bioelectronics, 22, 1224-1235. DOI: 10.1016/j.bios.2006.04.029.

Gupta, G., Rajendran, V., \& Atanassov, P. (2003). Laccase biosensor on monolayer-modified gold electrode. Electroanalysis, 15, 1577-1583. DOI: 10.1002/elan.200302724.

Gupta, G., Rajendran, V., \& Atanassov, P. (2004). Bioelectrocatalysis of oxygen reduction reaction by laccase on gold electrodes. Electroanalysis, 16, 1182-1185. DOI: 10.1002/elan.200403010.

Gutierrez-Sanchez, C., Pita, M., Vaz-Dominguez, C., Shleev, S., \& De Lacey, A. L. (2012). Gold nanoparticles as electronic bridges for laccase-based biocathodes. Journal of the American Chemical Society, 134, 17212-17220. DOI: $10.1021 /$ ja307308j.

Katz, E., \& Willner, I. (2003). Biofuel cells based on monolayerfunctionalized biocatalytic electrodes. In K. E. Geckeler (Ed.), Advanced macromolecular and supramolecular materials and processes (pp. 175-196). New York, NY, USA: Kluwer Academic/Plenum Publishers.

Mate, D. M., Gonzalez-Perez, D., Falk, M., Kittl, R., Pita, M., De Lacey, A. L., Ludwig, R., Shleev, S., \& Alcalde, M. (2013). Blood tolerant laccase by directed evolution. Chemistry $\&$ Biology, 20, 223-231. DOI: 10.1016/j.chembiol.2013.01.001.

Pita, M., Gutierrez-Sanchez, C., Toscano, M. D., Shleev, S., \& De Lacey, A. L. (2013). Oxygen biosensor based on bilirubin oxidase immobilized on a nanostructured gold electrode. Bioelectrochemistry, 94, 69-74. DOI: 10.1016/j.bioelechem.2013. 07.001 .

Shleev, S. V., Morozova, O. V., Nikitina, O. V., Gorshina, E. S., Rusinova, T. V., Serezhenkov, V. A., Burbaev, D. S., Gazaryan, I. G., \& Yaropolov, A. I. (2004). Comparison of physico-chemical characteristics of four laccases from different basidiomycetes. Biochimie, 86, 693-703. DOI: 10.1016/j.biochi.2004.08.005.

Shukla, A. K., Suresh, P., Berchmans, S., \& Rajendran, A. (2004). Biological fuel cells and their applications. Current Science, 87, 455-468.

Solomon, E. I., Sundaram, U. M., \& Machonkin, T. E. (1996). Multicopper oxidases and oxygenases. Chemical Reviews, 96, 2563-2606. DOI: $10.1021 / \mathrm{cr} 950046$ o.

Vaz-Dominguez, C., Campuzano, S., Rüdiger, O., Pita, M., Gorbacheva, M., Shleev, S., Fernandez, V. M., \& De Lacey, A. L. (2008). Laccase electrode for direct electrocatalytic reduction of $\mathrm{O}_{2}$ to $\mathrm{H}_{2} \mathrm{O}$ with high-operational stability and resistance to chloride inhibition. Biosensors and Bioelectronics, 24, 531-537. DOI: 10.1016/j.bios.2008.05.002.

Wu, X., Hu, Y., Jin, J., Zhou, N., Wu, P., Zhang, H., \& Cai, C. (2010). Electrochemical approach for detection of extracellular oxygen released from erythrocytes based on graphene film integrated with laccase and 2,2-azino-bis(3ethylbenzothiazoline-6-sulfonic acid). Analytical Chemistry, 82, 3588-3596. DOI: 10.1021/ac100621r. 